\title{
Photodegradation of Chloridazon Using Coreshell Magnetic Nanocompsites
}

\author{
Dina Mamdouh Fouad' ${ }^{\text {and Mona Bakr Mohamed² }}$ \\ ${ }^{1}$ Chemistry Department, Faculty of Science, Assiut University, 71516 Assiut, Egypt \\ ${ }^{2}$ National Insitute of Laser Enhanced Science, NILES, Cairo University, 12613 Cairo, Egypt \\ Correspondence should be addressed to Dina Mamdouh Fouad, dinafouad93@hotmail.com
}

Received 5 March 2011; Accepted 2 June 2011

Academic Editor: Menka Jain

Copyright (C) 2011 D. M. Fouad and M. B. Mohamed. This is an open access article distributed under the Creative Commons Attribution License, which permits unrestricted use, distribution, and reproduction in any medium, provided the original work is properly cited.

\begin{abstract}
A new synthesized magnetic nanoparticle of $\mathrm{Fe}_{3} \mathrm{O}_{4}$ and coreshell $\mathrm{Fe}_{3} \mathrm{O}_{4} @ \mathrm{Au}$ is prepared chemically. A comparative study between the photocatalytic activity between $\mathrm{Fe}_{3} \mathrm{O}_{4}$ and core shell $\mathrm{Au}-\mathrm{Fe}_{3} \mathrm{O}_{4}$ nanoparticles has been studied on the effect of UV and sun light on the photodegradation of chloridazon. The particle has been prepared using chemical methods and the particle size and shape have been examined via transmission electron microscopy (TEM). Analysis of the degradation of 20 ppm chloridazon under ultraviolet (UV) and visible light was analyzed with high-performance liquid chromatography (HPLC) and UV-Visible Spectra. Influence of different parameters on the activity photodegradation rate has been studied. The results indicate that the $\mathrm{Fe}_{3} \mathrm{O}_{4} @ \mathrm{Au}$ nanoparticles are much more active catalyst in presence of sun light than pure $\mathrm{Fe}_{3} \mathrm{O}_{4}$ nanomaterials which have maximum absorption at $560 \mathrm{~nm}$.
\end{abstract}

\section{Introduction}

Magnetic nanoparticles (NPs) have attracted significant interest, due to their numerous attributes such as their low toxicity and biocompatibility; the increasing attention in these materials as well as other composites is determined by the novel magnetic, electronic, optical, and chemical properties, which are different to those of the bulk materials because of the extreme small sizes and the large specific surface areas, and magnetic properties that enable them to be directed by an external magnetic field, in addition to their possibility to separate them from a reaction mixture [1-7]. Iron oxide nanoparticles could be easily oxidized by oxygen present in air and also can react between its self-forming aggregates. Many trials have been carried out to modify the surface during the synthesis or coating process [8-10]. A special class of particular interest of nanocomposite materials is nanoshell particles or core/shell nanocomposites. These core/shell nanocomposites are highly functional materials consisting of thin coatings (1-20 nm) of one particular material deposited on core particles of another different material utilizing certain procedures $[11,12]$.
Nanocomposites core/shell has attracted a lot of attention owing to their novel-tailored properties which are different from the single-component counterparts (the single core or shell). Now it is possible to synthesize these nanocomposites in desired size and shape and with controlled improved properties such as increased stability, surface area, magnetic, optical, and catalytic properties [13]. Gold surface allows the attachment of molecules with a relative ease using a variety of thiol linkers [14-16]; gold exhibits strong absorption in the visible region. This strong color originates from the excitation of the electrons in the conduction band and is called surface plasmon resonance. The surface plasmon resonance is the coherent excitation of the free surface electrons leading to coherent oscillation [17-20].

The herbicide n-chloridazon (5-amino-4-chloro-2-phenyl-3(2H)-pyridazinone; $n$-CLZ) is a selective systemic herbicide, which can cause apathy, dyspnoea, hyperventilation, hypersalivation (sheep-foam hypersalivation), paralysis, tonic-clonic convulsions, and death in clonic convulsions $[21,22]$.

Available fate data indicate that $\mathrm{n}$-CLZ is mobile in a variety of soil types and therefore, has the potential to enter 
<smiles>Nc1cnn(-c2ccccc2)c(=O)c1Cl</smiles>

FIgURE 1: Structure of chloridazon.

surface and groundwater [23, 24]. Few scientific reports deal with the presence and photodegradation of chloridazon [25]. Our main goal is to find away to eliminate the excess of chloridazon from water and soil using sunlight. It was essential to find a photocatalysis used for photodegradation of chloridazon to untoxic primary material such as $\mathrm{CO}_{2}$ and $\mathrm{H}_{2} \mathrm{O}$. In this work, we synthesize $\mathrm{Fe}_{3} \mathrm{O}_{4}$ nanoparticles capped with PVP and use this material as a catalyst. The prepared particles have been used as a seed to grow layer of gold shell on their surfaces. Comparative study between the catalytic activity of both particles has been evaluated in presence of UV and visible sunlight.

\section{Experimental}

2.1. Materials. n-chloridazon (5-amino-4-chloro-2-phenyl$3(2 \mathrm{H})$-pyridazinone; n-CLZ) was obtained from Fluka ( $99 \%$ HPLC grade) and used as received; hydrogen tetrachloroaurate trihydrate $\left(\mathrm{HAuCl}_{4} \cdot 3 \mathrm{H}_{2} \mathrm{O}\right)$; from Sigma-Aldrich, (99.9\%), Polyvinyl pyrrolidone, PVP-K30; from Fluka (Av. Wt. 22000); Trisodium citrate from Sigma-Aldrich, (99\%), Sterile sodium chloride physiological saline $0.9 \%$ (ADWIC) and Ferric chloride anhydrous from LOBA Chemicals (98\%); Sodium borohydride from Sigma (98\%), Sodium carbonate from Sigma (99\%), and L-Ascorbic acid from Sigma-Aldrish.

HPLC grade solvents (purity 99\%) such as methanol, ethanol, were purchased from Aldrich and high purity water are used in the experiments purified with the milli-Q system. All chemicals were used without any further purification (Figure 1).

\subsection{Synthesis of Nanoparticles}

2.2.1. Synthesis of Gold Nanoparticles by Citrate Method. Spherical gold nanoparticles in aqueous solution were prepared according to a method described by Turkevich. Simply, the method is a chemical reduction of gold ions by sodium citrate in aqueous solution. Sodium citrate serves also as a capping materials prevents aggregation and further growth of the particles. $5 \mathrm{~mL}$ of $1 \%$ sodium citrate solution was added to a boiling solution $40 \mathrm{~mL}$ of a chlorouric acid $\left(\mathrm{HAuCl}_{4}\right)$ solution containing $5 \mathrm{mg}$ of gold ions. The solution was boiled for 30 minutes and was then left to cool down to room temperature. The produced gold particles have average diameter of $15.0 \mathrm{~nm}$ as determined by TEM analysis.
2.2.2. Preparation of $\mathrm{Fe}_{3} \mathrm{O}_{4}$. Magnetite nanospheres $8 \pm 2 \mathrm{~nm}$ size is synthesized by coprecipitation method using ascorbic acid reduction of $\mathrm{FeCl}_{3}$ (231). A $100 \mathrm{~mL}$ beaker is cleaned in aqua regia ( 3 parts $\mathrm{HCl}, 1$ part $\mathrm{HNO}_{3}$ ) and rinsed with DDI water. $0.25 \mathrm{~g}$ of $\mathrm{FeCl}_{3}$ powder is dissolved in $25 \mathrm{~mL}$ Sterile Saline with stirring for five minutes at room temperature. $0.6 \mathrm{~g} \mathrm{NaCO}_{3}$ powder dissolved $10 \mathrm{~mL}$ Sterile Saline is added to $\mathrm{FeCl}_{3}$ solution with continued stirring for 10 minutes; the solution turned viscous with brown color. Directly adding $0.12 \mathrm{~g}$ powder of ascorbic acid to the previous solution with vigorous stirring for 15 minutes, the color of solution turned black, and formation of magnetite nanoparticles is capped with ascorbic acid. We complete the solution to $50 \mathrm{~mL}$ with Sterile Saline in measuring flask.

2.2.3.Preparation of $\mathrm{Fe}_{3} \mathrm{O}_{4} @ A u$ Nanoparticles. The magnetooptical (magnetite/gold) core shell nanocomposites were prepared chemically by reducing gold (III) chloride to gold in the presence of presynthesized magnetite nanoparticles (MNPs). During the reduction process, a reddish color is developed indicating the formation of $\mathrm{Au}$ nanoparticles; magnetite nanoparticles behave like "seeds" or nucleation sites for the resultant $\mathrm{Fe}_{3} \mathrm{O}_{4} @ \mathrm{Au}$ nanocomposites. Ultraviolet-visible (UV-vis) absorption spectrometry confirms the formation of the resultant $\mathrm{Fe}_{3} \mathrm{O}_{4} / \mathrm{Au}$ nanocomposites. TEM has been used to characterize as-prepared bimetallic nanocomposites. $10.0 \mathrm{~mL}$ of presynthesized MNPs were placed in a $100 \mathrm{~mL}$ flask equipped with a small magnet bar for the sake of stirring. Then, a $10.0 \mathrm{~mL}$ Au precursor solution (aq. soln. of $\mathrm{HAuCl}_{4} \cdot 3 \mathrm{H}_{2} \mathrm{O}, 1 \mathrm{mM}$ with $1.0 \mathrm{PVP}$ ) was added into the flask. The reaction mixture was allowed to boil under reflux. Upon boiling, up to $1.0 \mathrm{~mL}$ of the reducing solution $(0.1 \mathrm{M}$ trisodium citrate in water) was slowly injected into the flask under stirring to avoid mass production of pure gold nanoparticles. The color of the solution turned to reddish upon reduction. The absorption spectrum is recorded, and additional citrate may be added in order to predominate the characteristic plasmon band for the GNPs, which indicate the surface coverage of MNPs with a layer of gold.

Investigation and examination of particle size and shape have been investigated using Transmission electron microscopy (TEM) (JEM 100CXII) operated at High Voltage $120 \mathrm{KV}$. Absorption spectra have been measured using UVVis spectrophotometer.

2.2.4. Photodegradation Mechanisem of Chloridazon. The phgotodegradation of chloridazon has been monitored using UV-Visible spectrophotometer (Evolution 300) (thermo scientific) and HPLC (Bischoff). Different concentrations of chloridazon $\left(1 \times 10^{-4}\right.$ and $\left.5 \times 10^{-4}\right)$ have been prepared by dissolving the required amounts in $10 \mathrm{~mL}$ methanolicsolution.

Equal amounts of chloridazon solution and the catalyst have been mixed and irradiated at the same time to the light. The UV-Vis absorption spectra have been recorded at different time intervals. 


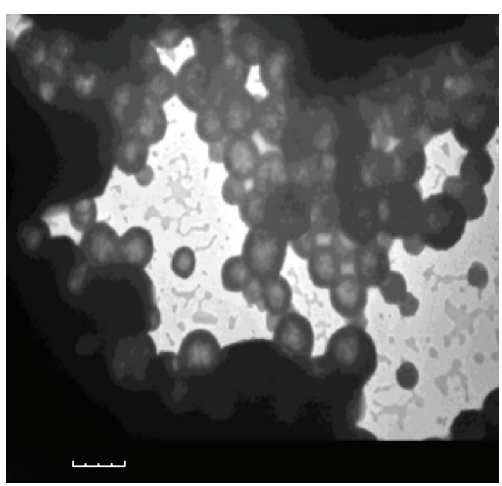

(a)

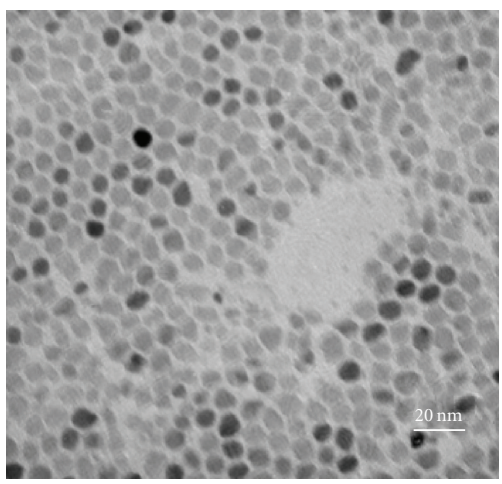

(b)

FIGURE 2: (a, b) TEM image of the prepared magnetite nanoparticles capped with ascorbic acid shows that these particles have spherical shape with average size of $8.0 \pm 2.0 \mathrm{~nm}$.

\section{Results}

3.1. Characterization of Magnetite Nanoparticles. Physicochemical properties of magnetite nanoparticles can be characterized via TEM imaging and vibrating sample magnatometry (VSM) measurements.

The TEM images of the synthesized magnetite nanoparticles show that these particles have average size of $8.0 \pm 2.0 \mathrm{~nm}$ with spherical shape as shown in Figures 2(a) and 2(b).

The magnetic measurements are done using VSM on an unoriented, random assembly of particles at room temperature; a hysteresis loop was generated from which the intrinsic coercivity $(\mathrm{Hc})$, remnant magnetization $(\mathrm{Mr})$, and saturation magnetization (Ms) were calculated. The saturation magnetization of the product is $5.2 \mathrm{emu} / \mathrm{g}$ much smaller than that $(68.7 \mathrm{emu} / \mathrm{g})$ of the $\mathrm{Fe}_{3} \mathrm{O}_{4}$ nanoparticles sized about $70 \mathrm{~nm}$ prepared through a hydrothermal method without any surfactants [26].

3.2. Characterization of the Prepared of Biocompatible Magneto-Optical Nanocomposite. Magnato-optical core shell nanocomposite formed of Magnetite and gold is synthesized, where aqueous solution of gold nanoparticles capped with citrate and the core shell Magnetite-gold nanoshell were prepared as shown in the experimental section. The average size of the particles is determined from the transmission

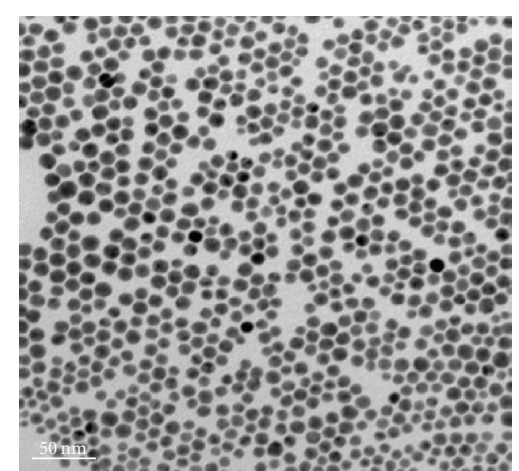

(a)

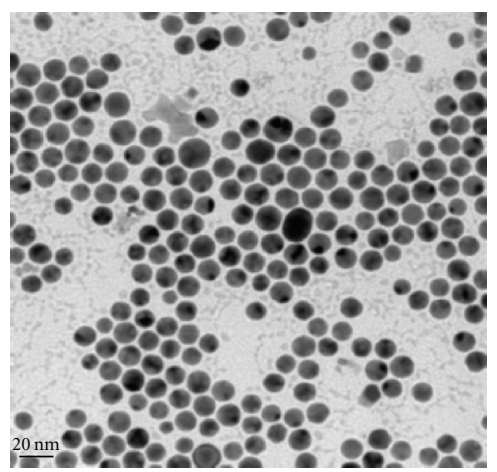

(b)

FIGURE 3: TEM images of Magnato-optical nanocomposite (magnetite-gold core shell nanocompostite) and is found to be (a) $15 \mathrm{~nm}$, (b) $1.1 \mathrm{~nm}$ for the spherical gold nanoparticles, and core shell.

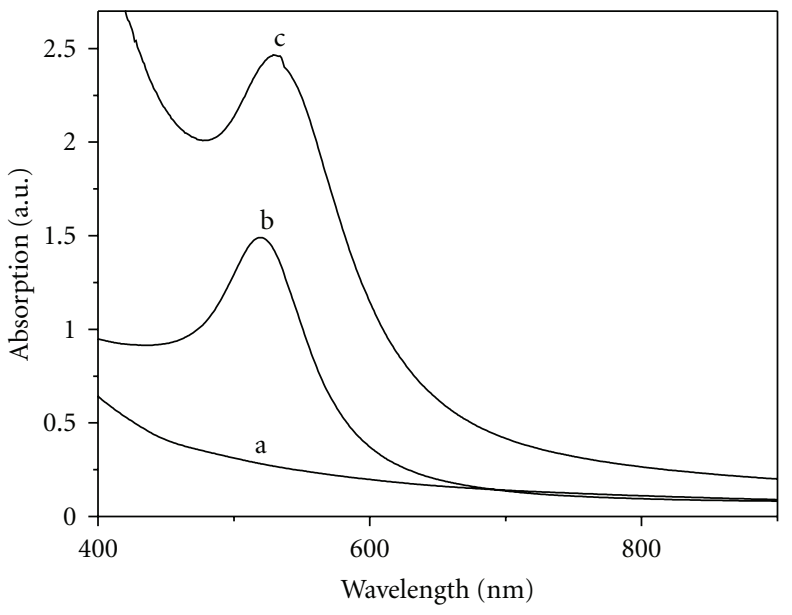

Figure 4: Absorption spectra of (a) $\mathrm{Fe}_{3} \mathrm{O}_{4}$ and (b) $\mathrm{Fe}_{3} \mathrm{O}_{4} @ \mathrm{Au}$ and (c) Au.

electron microscopic (TEM) images and is found to be $15 \mathrm{~nm}$ $\pm 1.1 \mathrm{~nm}$ for the spherical gold nanoparticles, and core shell is about $18 \mathrm{n}$, (Figures 3(a) and 3(b)). Figure 4 presents the absorption band of $\mathrm{Fe}_{3} \mathrm{O}_{4} @ \mathrm{Au}, \mathrm{Fe}_{3} \mathrm{O}_{4}$, and $\mathrm{Au}$.

3.3. Exposure to Different Concentrations Nanocomposites. Different factors which affect the rate of photodegradation 


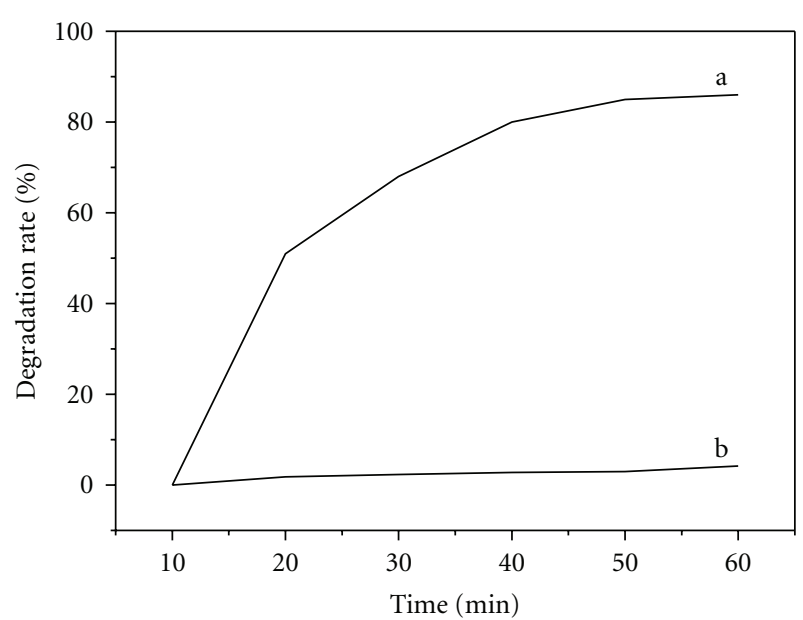

Figure 5: Effect of different concentration of $\mathrm{Fe}_{3} \mathrm{O}_{4} @ \mathrm{Au}$ on degradation of $10^{-5} \mathrm{M}$ chloridazon: (a) $10^{-4} \mathrm{M} \mathrm{Fe}_{3} \mathrm{O}_{4} @ \mathrm{Au}$ and (b) $10^{-5} \mathrm{M} \mathrm{Fe}_{3} \mathrm{O}_{4} @ \mathrm{Au}$.

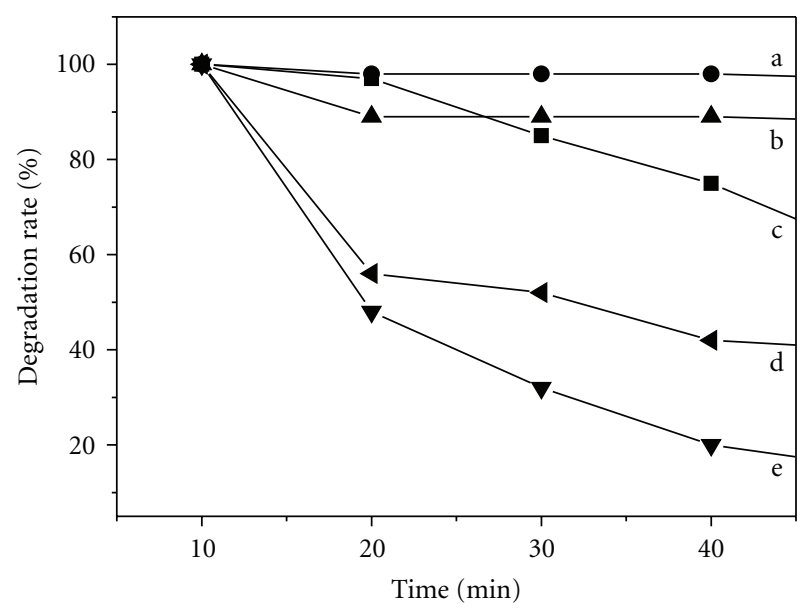

Figure 6: Normalized Curve shows Effect of different light sources, (a) in presence of $\mathrm{Fe}_{3} \mathrm{O}_{4}$ in dark (b) in presence of $\mathrm{Fe}_{3} \mathrm{O}_{4} @ \mathrm{Au}$ in dark (c) in presence of $\mathrm{Fe}_{3} \mathrm{O}_{4} @ \mathrm{Au}$ in sun, (d) in presence of $\mathrm{Fe}_{3} \mathrm{O}_{4}$ in UV lamp, and (e) in presence of $\mathrm{Fe}_{3} \mathrm{O}_{4} @ \mathrm{Au}$ in UV lamp.

such as the catalyst concentration and the irradiation time have been investigated [27-29]. Figure 5 shows the degradation of chloridazon with different concentrations $\mathrm{Fe}_{3} \mathrm{O}_{4} @ \mathrm{Au}$ nanoparticle. The rate of photodegradation has been determined by the exposure of the chloridazon-catalyst mixture to light, the rate of photodegradation and how it depends on the catalyst concentration have been studied. It is worth to mention that only $10 \%$ of the pesticides are degradated using $10^{-5} \mathrm{M}$, but in case of the $10^{-4}, 80 \%$ of the pesticides are degradated in less than one hour. Degradation of chloridazon with various amounts of the catalysts was studied. The results clearly emphasize that higher amount of the nanoparticles increases the production of the free radicals which accelerates the rate of degradation reaction [30].
TABLE 1: RT and integration area of HPLC peaks about products after 15 mins of photoreaction in presence of $\mathrm{Fe}_{3} \mathrm{O}_{4} @ \mathrm{Au}$.

\begin{tabular}{lcc}
\hline $\mathrm{RT}(\min )$ & 3.58 & 7.2 \\
Integration area (\%) & 19 & 79.14 \\
\hline
\end{tabular}

TABLE 2: RT and integration area of HPLC peaks about products after 60 mins of photoreaction in presence of $\mathrm{Fe}_{3} \mathrm{O}_{4} @ \mathrm{Au}$.

\begin{tabular}{lcc}
\hline RT (min) & 3.58 & 7.2 \\
Integration area (\%) & 36 & 49.47 \\
\hline
\end{tabular}

3.4. Exposure to Different Light Sources. Photocatalytic reaction rate depends largely on the radiation absorption of the photocatalyst [31]. It has been reported that the degradation rate Increases as the light intensity increases.

By subjecting the mixtures containing the chloridazon with the nanocomposites to sun light degradation will only occur for visible light responsive catalyst which is in our case $\mathrm{Fe}_{3} \mathrm{O}_{4} @$ Au. Figure 6(c) presented that about 20\% was degraded after one hour. This leads to the higher photocatalytic activity under UV-visible light. Figures 6(d) and 6(e) show that UV-C attributed a high rate of degradation of chloridazon for both nanoparticles $\mathrm{Fe}_{3} \mathrm{O}_{4}$ and $\mathrm{Fe}_{3} \mathrm{O}_{4} @ \mathrm{Au}$ since after 1 hour about $80 \%$ of chloridazon was degraded since high-energy source would excite more electrons from a vacancies band to conduction band; simultaneously the quantum efficiency of the nanocomposites is increased [32].

3.5. Exposure to Different Irradiation Time. The effect of irradiation time under the different conditions of nanocomposite concentrations and different light sources was investigated. The results shown in Figure 7 suggest that the degradation degree obviously increases with increasing the irradiation time and the increase in the rate of degradation showed the significance for using $\mathrm{Fe}_{3} \mathrm{O}_{4}$ and $\mathrm{Fe}_{3} \mathrm{O}_{4} @ \mathrm{Au}$ as nanocatalysts. To validate our investigations, we compared the results obtained with those obtained by a previously prepared photo-nanocatalyst synthesized by our group. As shown in Figure 7(c) chloridazon is degraded with $\mathrm{ZnO@Au}$ nanoprticle in quite a same trend as $\mathrm{Fe}_{3} \mathrm{O}_{4} @ \mathrm{Au}$.

3.6. HPLC Measurements. Chloridazon has one sharp peak at retention time 7; the decrease in the area of this band intensity and the area under the peak reflects the decomposition of the chloridazon, by subjecting the chloridazon nanopcomoposite mixture to UV lamp for 1 hour and comparing the results with the degradation of chloridazon subjected to UV lamp without any addition of nanoparticle. The results shown in Figure 8 illustrates that by the addition of the different synthesized nanoparticals to chloridazon a marked decrease in the peak area and the integration area percentage was obtained, while choridazon showed photostability under the same conditions without any nanoparticals (Tables 1 and 2). 

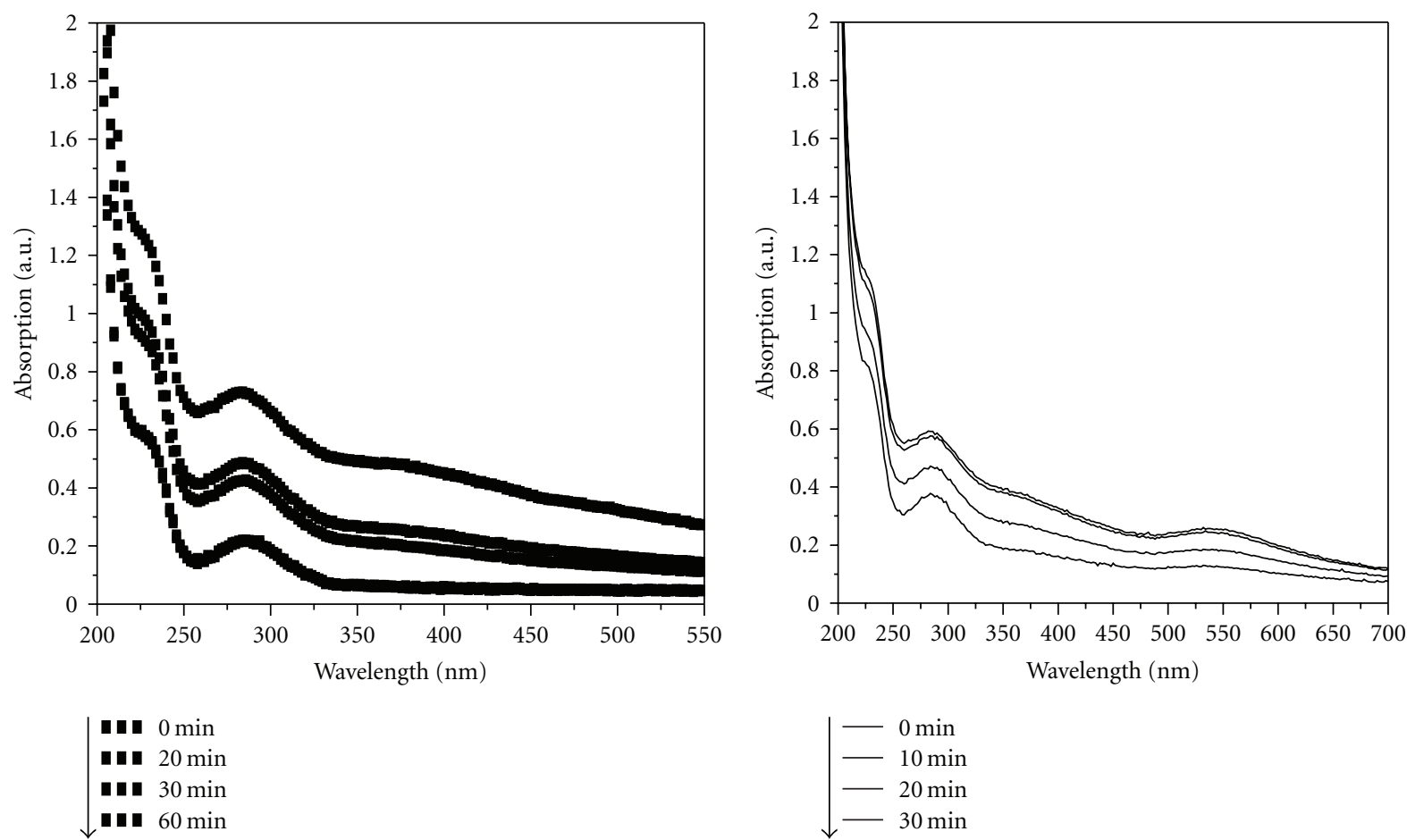

(a)

(b)

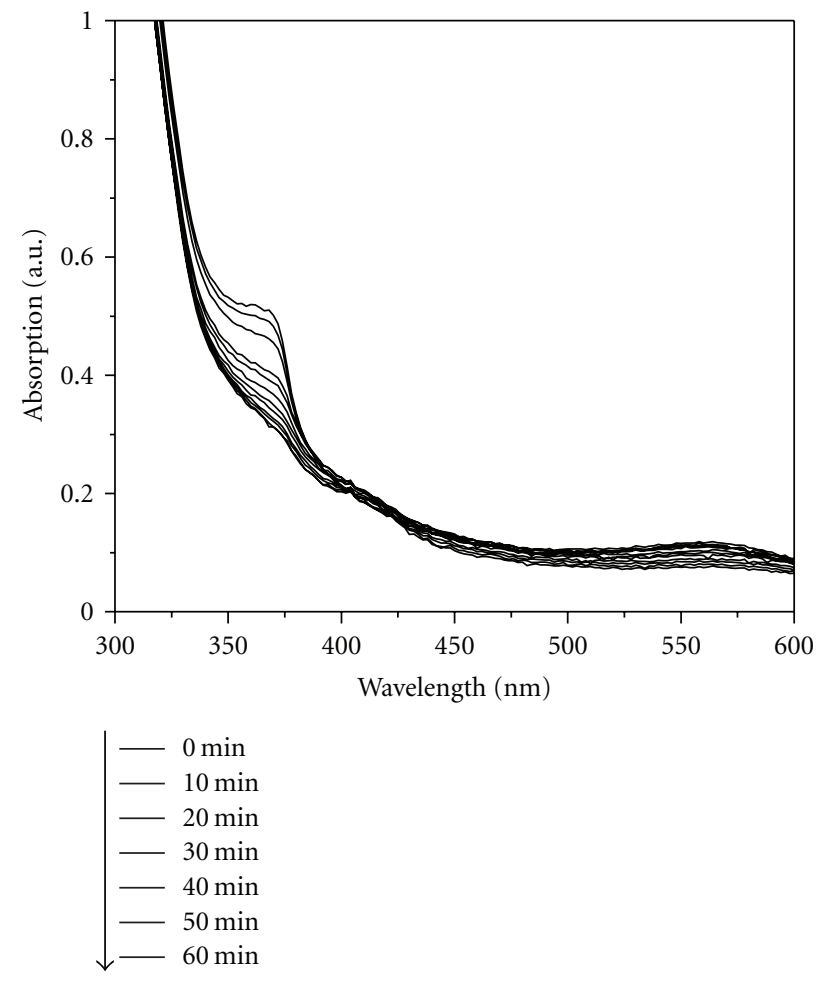

(c)

Figure 7: Time-dependent photodegradtion of cholridazon in UV lamp. (a) Addition of $10^{-4} \mathrm{Fe}_{3} \mathrm{O}_{4}$. (b) Addition of $10^{-4} \mathrm{Fe}{ }_{3} \mathrm{O}_{4} @ A u$. (c) Addition of ZnO@Au. 


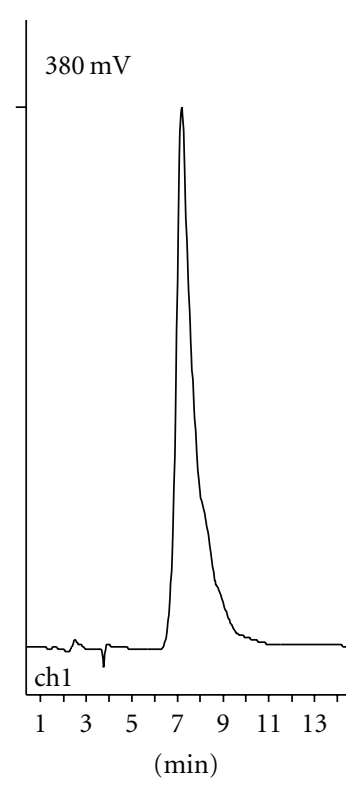

(a)

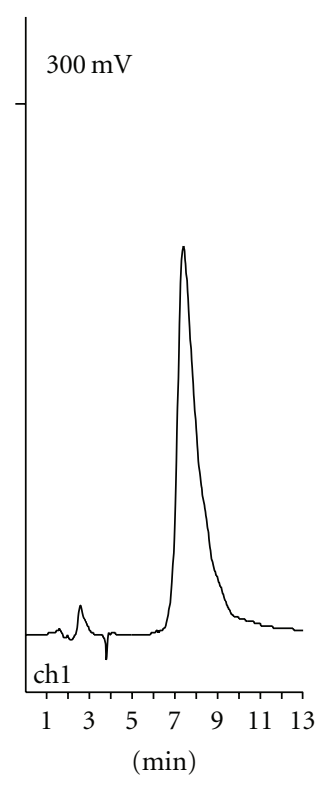

(b)

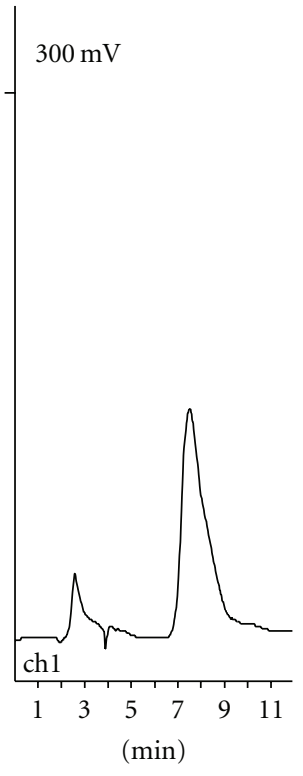

(c)

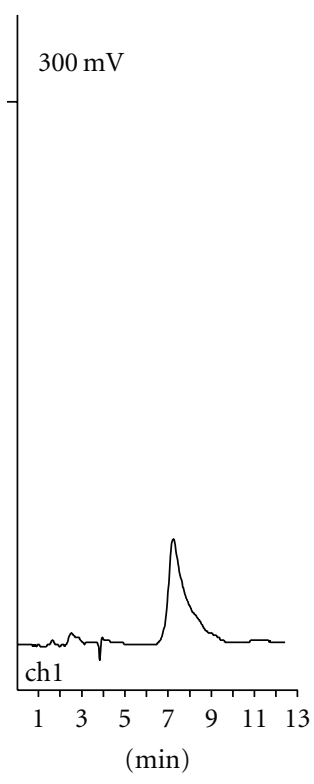

(d)

FiguRE 8: HPLC chromatograms for the photodegradation of $20 \mathrm{mg} / \mathrm{L}^{-1}$ chloridazon using different synthesized nanoparticals: (a) chloridazon, (b) in absence of nanocomopsites, (c) in presence of $\mathrm{Fe}_{3} \mathrm{O}_{4}$, and (d) in presence of $\mathrm{Fe}_{3} \mathrm{O}_{4} @ \mathrm{Au}$.

\section{Conclusion}

$\mathrm{Fe}_{3} \mathrm{O}_{4} @ \mathrm{Au}$ has turned out to have high efficiency in photodegradation in comparison to the $\mathrm{Fe}_{3} \mathrm{O}_{4}$ due to the presence of the gold which has the plasmonic phenomena having a great influence in accelerating the oxidation of the pesticides.

\section{References}

[1] D. Q. Jian, X. Meng, L. Ru-Ping, P. Hua-Ping, and L. Fen, “Synthesis and characterization of ferrocene modified $\mathrm{Fe}_{3} \mathrm{O}_{4} @ \mathrm{Au}$ magnetic nanoparticles and its application," Biosensors and Bioelectronics, vol. 24, no. 8, pp. 2649-2653, 2009.

[2] W. Nan, Z. Lihua, W. Dali, W. Mingqiong, L. Zhifen, and T. Heqing, "Sono-assisted preparation of highly-efficient peroxidase-like $\mathrm{Fe}_{3} \mathrm{O}_{4}$ magnetic nanoparticles for catalytic removal of organic pollutants with $\mathrm{H}_{2} \mathrm{O}_{2}$, Ultrasonics Sonochemistry, vol. 17, no. 3, pp. 526-533, 2010.

[3] W. Nan, Z. Lihua, W. Mingqiong, W. Dali, and T. Heqing, "Sono-enhanced degradation of dye pollutants with the use of $\mathrm{H}_{2} \mathrm{O}_{2}$ activated by $\mathrm{Fe}_{3} \mathrm{O}_{4}$ magnetic nanoparticles as peroxidase mimetic," Ultrasonics Sonochemistry, vol. 17, no. 1, pp. 78-83, 2010.

[4] A. G. Tarek, F. Kyoko, K. Shigeru, S. Shigeo, and K. Toshinori, "Preparation and characterization of magnetically separable photocatalyst $\left(\mathrm{TiO}_{2} / \mathrm{SiO}_{2} / \mathrm{Fe}_{3} \mathrm{O}_{4}\right)$ : effect of carbon coating and calcination temperature," Journal of Hazardous Materials, vol. 154, no. 1-3, pp. 572-577, 2008.

[5] Z. Ling, W. Wenzhong, Z. Lin, S. Meng, and S. Songmei, " $\mathrm{Fe}_{3} \mathrm{O}_{4}$ coupled BiOCl: a highly efficient magnetic photocatalyst," Applied Catalysis B, vol. 90, no. 3-4, pp. 458-462, 2009.

[6] T. F. Hsu, T. L. Hsiung, W. James, C. H. Huang, and H. P. Wang, "In situ XANES studies of $\mathrm{TiO}_{2} / \mathrm{Fe}_{3} \mathrm{O}_{4} @ \mathrm{C}$ during photocatalytic degradation of trichloroethylene," Nuclear
Instruments and Methods in Physics Research A, vol. 619, no. 1-3, pp. 98-101, 2010.

[7] W. Jiang, C. Jiang, Z. Cao, X. Gong, and Z. Zhang, "Fabrication and characterization of photocatalytic activity of $\mathrm{Fe}_{3} \mathrm{O}_{4}$ doped CdS hollow spheres," Journal of Physics and Chemistry of Solids, vol. 70, no. 3-4, pp. 782-786, 2009.

[8] L. Zhang, W. Wang, M. Shang, S. Sun, and J. Xu, " $\mathrm{Bi}_{2} \mathrm{WO}_{6} @$ carbon $/ \mathrm{Fe}_{3} \mathrm{O}_{4}$ microspheres: preparation, growth mechanism and application in water treatment," Journal of Hazardous Materials, vol. 172, no. 2-3, pp. 1193-1197, 2009.

[9] Z. Q Zou, M. Ibisate, Y. Zhou, R. Aebersold, Y. N. Xia, and H. Zhang, "Synthesis and evaluation of superparamagnetic silica particles for extraction of glycopeptides in the microtiter plate format," Analytical Chemistry, vol. 80, no. 4, pp. 1228-1234, 2008.

[10] D. K. Kim, Y. Zhang, J. Kehr, T. Klason, B. Bjelke, and M. Muhammed, "Characterization and MRI study of surfactantcoated superparamagnetic nanoparticles administered into the rat brain," Journal of Magnetism and Magnetic Materials, vol. 225, no. 1-2, pp. 256-261, 2001.

[11] R. Davies, G. A. Schurr, P. Meenan et al., "Engineered particle surfaces," Advanced Materials, vol. 10, no. 15, pp. 1264-1270, 1998.

[12] A. C. Templeton, W. P. Wuelfing, and R. W. Murray, "Monolayer-protected cluster molecules," Accounts of Chemical Research, vol. 33, no. 1, pp. 27-36, 2000.

[13] S. Kalele, S. W. Gosavi, J. Urban, and S. K. Kulkarni, "Nanoshell particles: synthesis, properties and applications," Current Science, vol. 91, no. 8, pp. 1038-1052, 2006.

[14] G. K. Kouassi and J. Irudayaraj, "Magnetic and gold-coated magnetic nanoparticles as a DNA sensor," Analytical Chemistry, vol. 78, no. 10, pp. 3234-3241, 2006.

[15] C. Minard-Basquin, R. Kügler, N. N. Matsuzawa, and A. Yasuda, "Gold-nanoparticle-assisted oligonucleotide immobilisation for improved DNA detection," IEEE Proceedings Nanobiotechnology, vol. 152, no. 2, pp. 97-103, 2005. 
[16] L. M. Demers, C. A. Mirkin, R. C. Mucic et al., "A fluorescence-based method for determining the surface coverage and hybridization efficiency of thiol-capped oligonucleotides bound to gold thin films and nanoparticles," Analytical Chemistry, vol. 72, no. 22, pp. 5535-5541, 2000.

[17] U. Kreibig and M. Vollmer, Optical Properties of Metal Clusters, Springer, New York, NY, USA, 1995.

[18] G. C. Papavassiliou, "Optical properties of small inorganic and organic metal particles," Progress in Solid State Chemistry, vol. 12, no. 3-4, pp. 185-271, 1979.

[19] C. F. Bohren and D. R. Huffman, Absorption and Scattering of Light by Small Particles, John Wiley \& Sons, New York, NY, USA, 1983.

[20] J. A. Creighton and D. G. Eadon, "Ultraviolet-visible absorption spectra of the colloidal metallic elements," Journal of the Chemical Society, Faraday Transactions, vol. 87, no. 24, pp. 3881-3891, 1991.

[21] EPA, Registration Eligibility Decision (RED) Document for Pyrazon, US Environmental Protection Agency, 2005.

[22] H. Mlynarcikova, J. Legath, J. Guzy, N. Kovalkovicova, and S. Ivanko, "Effect of chloridazon on the animal organism," General Physiology and Biophysics, vol. 18, pp. 99-104, 1999.

[23] C. Tomlin, The e-Pesticide Manual. Version 2.2, British Crop Production Council, Hampshire, UK, 12th edition, 2002.

[24] F. F. Céspedes, M. V. Sánchez, S. P. García, and M. F. Pérez, "Modifying sorbents in controlled release formulations to prevent herbicides pollution," Chemosphere, vol. 69, no. 5, pp. 785-794, 2007.

[25] G. Buttiglieri, M. Peschka, T. Frömel et al., "Environmental occurrence and degradation of the herbicide n-chloridazon," Water Research, vol. 43, no. 11, pp. 2865-2873, 2009.

[26] J. Wan, Y. Yao, and G. Tang, "Controlled-synthesis, characterization, and magnetic properties of $\mathrm{Fe}_{3} \mathrm{O}_{4}$ nanostructures," Applied Physics A, vol. 89, no. 2, pp. 529-532, 2007.

[27] A. J. Maira, K. L. Yeung, J. Soria et al., "Gas-phase photooxidation of toluene using nanometer-size $\mathrm{TiO}_{2}$ catalysts," Applied Catalysis B, vol. 29, no. 4, pp. 327-336, 2001.

[28] J. Krýsa, M. Keppert, J. Jirkovský, V. Štengl, and J. Šubrt, “The effect of thermal treatment on the properties of $\mathrm{TiO}_{2}$ photocatalyst," Materials Chemistry and Physics, vol. 86, no. 2-3, pp. 333-339, 2004.

[29] M. Saquib and M. Muneer, " $\mathrm{TiO}_{2} /$ mediated photocatalytic degradation of a triphenylmethane dye (gentian violet), in aqueous suspensions," Dyes and Pigments, vol. 56, no. 1, pp. 37-49, 2003.

[30] B. Neppolian, H. Jung, and H. Choi, "Photocatalytic degradation of 4-chlorophenol using $\mathrm{TiO}_{2}$ and $\mathrm{Pt}-\mathrm{TiO}_{2}$ nanoparticles prepared by sol-gel method," Journal of Advanced Oxidation Technologies, vol. 10, no. 2, pp. 369-374, 2007.

[31] D. Curco, J. Gimenez, A. Addardak, S. Cervera-Marcch, and S. Esplugas, "Effects of radiation absorption and catalyst concentration on the photocatalytic degradation of pollutants," Catalysis Today, vol. 76, no. 2-4, pp. 177-188, 2002.

[32] X. Yibing and Y. Chunwei, "Photocatalysis of neodymium ion modified $\mathrm{TiO}_{2}$ sol under visible light irradiation," Applied Surface Science, vol. 221, no. 1-4, pp. 17-24, 2004. 

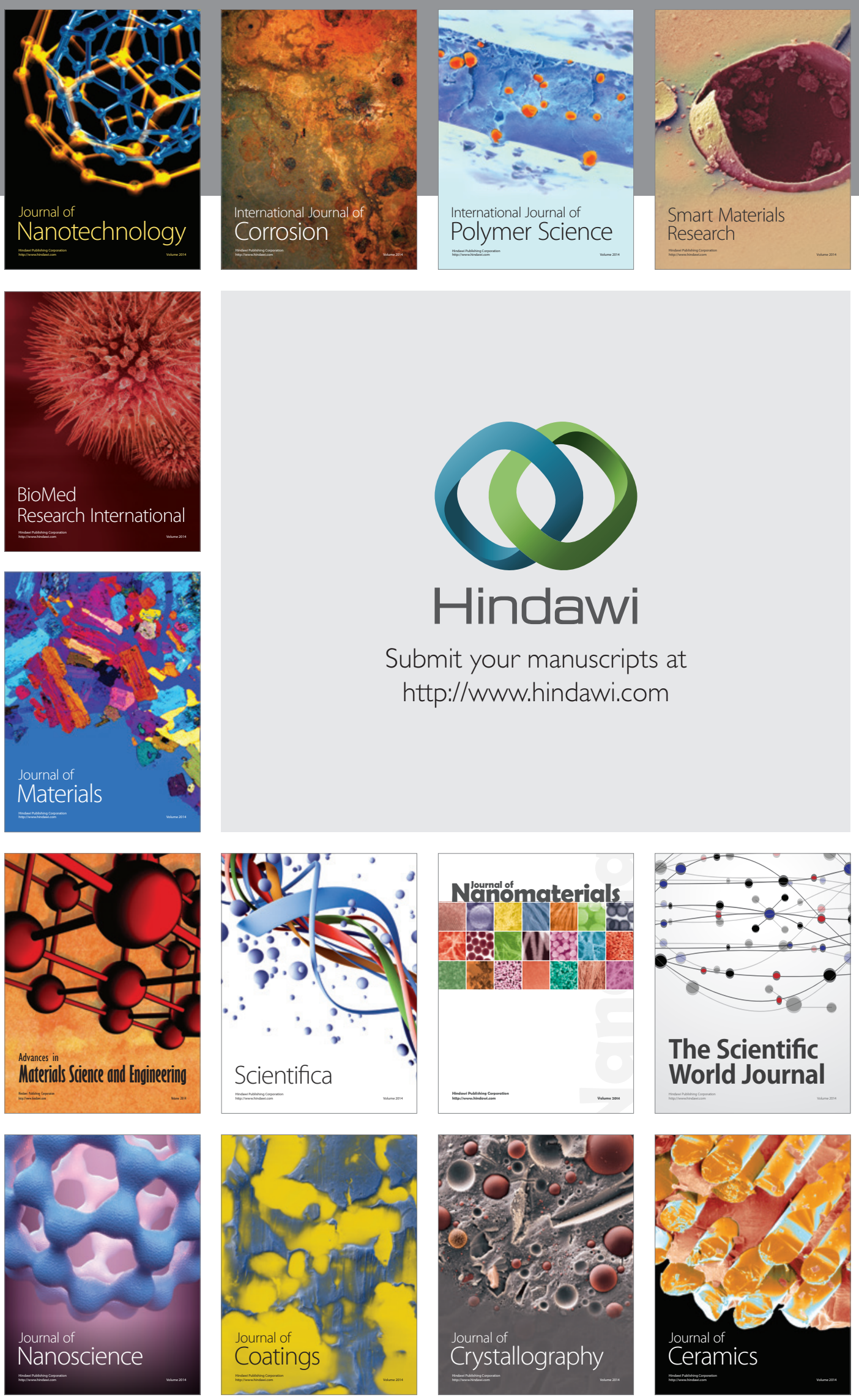

The Scientific World Journal

Submit your manuscripts at

http://www.hindawi.com

\section{World Journal}

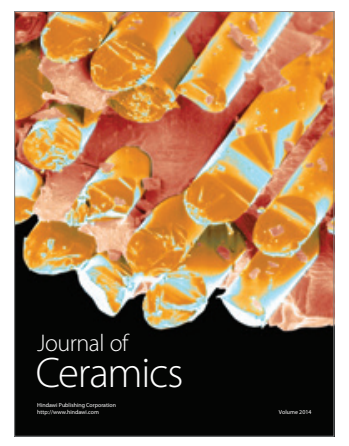

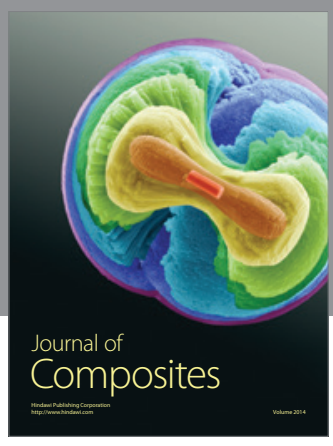
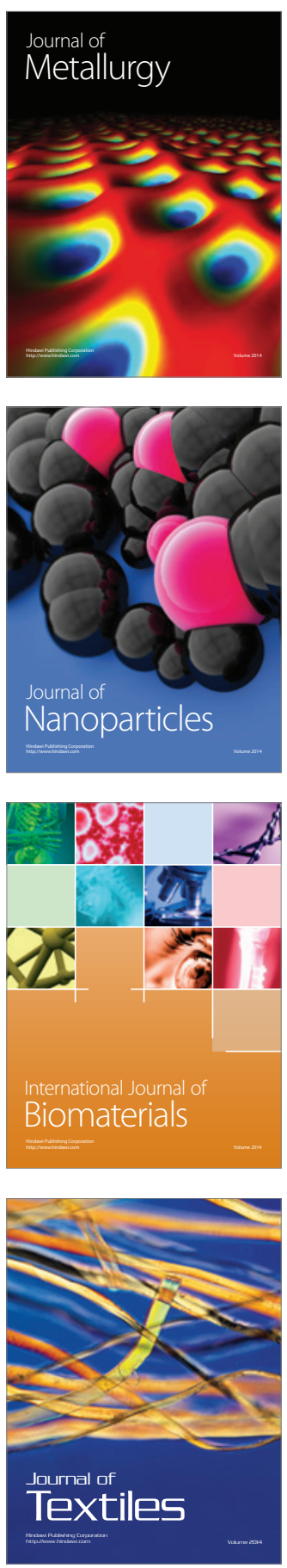